\title{
Inflammatory Morbidity due to Compound Mandibular Body Fractures: Does It Have a Relationship with Treatment Outcome?
}

\author{
Charles E. Anyanechi ${ }^{a}$ Birch D. Saheeb ${ }^{b}$ \\ ${ }^{a}$ Department of Dental Surgery, University of Calabar Teaching Hospital, Calabar, and ${ }^{\mathrm{b}}$ Department of Oral and \\ Maxillofacial Surgery, University of Benin Teaching Hospital, Benin City, Nigeria
}

\section{Key Words}

Mandible $\cdot$ Body fracture $\cdot$ Pain $\cdot$ Trismus $\cdot$ Complications

\begin{abstract}
Objective: The aim of this study was to evaluate the relationship between the degree of preoperative pain and trismus with the development of complications following the repair of isolated unilateral compound mandibular body fractures using a closed reduction technique. Subjects and Methods: This was a 7-year prospective study carried out at the Dental and Maxillofacial Surgery Clinic of the University of Calabar Teaching Hospital, Calabar, Nigeria. Of a total of 97 patients, $83(85.6 \%)$ subjects (66 males, 17 females, ratio 5:1) were preoperatively evaluated for trismus and pain in a blinded manner by a single examiner, and complications were recorded postoperatively. The data obtained were statistically analyzed with EPI Info 2008 software. Results: Of the 83 patients treated, 13 (15.7\%) developed complications. The fractures were most common in the age range of $21-40$ years $(n=45$, $54.2 \%)$. The age $(p=0.02)$ and gender $(p=0.01)$ distribution of the subjects was significant. The more severe the limitation of mouth opening $(p=0.03)$ and pain $(p=0.04)$ before treatment, the more complications developed, and these significantly affected treatment outcome. Impaired mastication and facial asymmetry $(n=17,41.5 \%)$ were the most
\end{abstract}

common complications. Conclusion: This study showed that posttrauma pain and trismus due to unilateral mandibular body fractures may be associated with the development of complications. An adequately powered prospective study treating patients at 5 or 7 days is required in order to make the case for later intervention.

(c) 2015 S. Karger AG, Basel

\section{Introduction}

Inflammatory morbidities associated with mandibular fractures have led the timing of the surgical repair of fractured segments to become a controversial issue in oral and maxillofacial surgical practice. Some authors support immediate repair of the fractured segments within $72 \mathrm{~h}$ while others advocate a longer time lag in order to allow a decrease in inflammatory morbidities of the surrounding orofacial tissues [1-4]. The influence of the surrounding tissue edema, pain and limitation of mouth opening (trismus) on the treatment outcome remains an issue of constant debate. The literature on the topic tend to discuss whether the edema that results in facial swelling, pain and trismus should be allowed to subside or not before treatment [2-4]. However, complications from mandibular fractures often develop before,

\begin{tabular}{ll}
\hline KARGER 125\% & $\begin{array}{l}\text { (1) 2015 S. Karger AG, Basel } \\
\text { 1011-7571/15/0243-0238\$39.50/0 Openger }\end{array}$ \\
$\begin{array}{l}\text { E-Mail karger@karger.com } \\
\text { www.karger.com/mpp }\end{array}$ & $\begin{array}{l}\text { This is an Open Access article licensed under the terms of the } \\
\text { Creative Commons Attribution-NonCommercial 3.0 Un- } \\
\text { ported license (CC BY-NC) (www.karger.com/OA-license), } \\
\text { applicable to the online version of the article only. Distribu- } \\
\text { tion permitted for non-commercial purposes only. }\end{array}$
\end{tabular}

Dr. Charles E. Anyanechi

Department of Dental Surgery

University of Calabar Teaching Hospital

Eastern Highway, Calabar 540001 (Nigeria)

E-Mail ceanyanechi@gmail.com 
during or after treatment $[3,5]$. Many studies have shown that these complications are attributable to many factors, such as the age of the patient, the type and site of the fracture, the medical status of the patient, substance abuse, teeth in the line of the fracture, the type and cost of treatment, inadequate reduction or stabilization, the competence of the surgeon, and poor patient compliance to instructions after treatment [5-11]. There appears to be no consensus in the literature on the most prevalent factors associated with complications following mandibular fracture. This plethora of reasons suggests that there may also be other contributory factors yet to be identified that adversely or favorably impact on the outcome of treatment.

However, the influence of the inflammatory response and its consequent morbidities in the orofacial region following traumatic injury cannot be overemphasized as it adversely impacts on facial esthetics and the function of the masticatory apparatus. The present study therefore evaluated the relationship between the degree of facial pain and trismus with the development of complications following the repair of isolated unilateral compound mandibular body fractures using a closed reduction technique over a period of 7 years.

\section{Subjects and Methods}

This is a prospective study that evaluated the relationship between the degree of preoperative facial pain and limitation of mouth opening (trismus) with the development of complications in patients who sustained an isolated unilateral mandibular body fracture and were treated by maxilla-mandibular fixation. The study was carried out at the Dental and Maxillofacial Surgery Clinic of the University of Calabar Teaching Hospital, Nigeria, which is a tertiary health institution, between January 2007 and December 2012. Ethical approval was obtained from the Research Ethics Committee of the hospital before the commencement of the study, and the study followed the 1975 Declaration of Helsinki on medical protocol and ethics. Written informed consent was obtained from all the subjects enrolled in the study.

Inclusion criteria were patients of all ages and either gender who sustained isolated unilateral compound mandibular body fractures and presented to the clinic within $48 \mathrm{~h}$ of the injury, and also those who were completely or partially dentate, and attended a minimum of eight follow-up visits. Exclusion criteria were patients who were edentulous or had isolated dentoalveolar fractures of the mandible, had pathological and comminuted mandibular body fractures, as well as those with debilitating medical and surgical conditions like diabetes mellitus, nephritis, asthma, HIV/AIDS, anemia, osteoporosis, malnutrition or substance abuse, those taking steroid/oral contraceptives, those with concomitant injuries in the oral and maxillofacial region and other parts of the body, and patients taking nonsteroidal anti-inflammatory drugs or other anti-inflammatory medications before treatment.

Inflammatory Morbidity and Mandibular Body Fractures
Out of a total of 97 subjects that presented, 83 (85.6\%) met the inclusion criteria for the study while 14 were excluded. The age of the patients ranged from 15 to 76 years, 66 were male and 17 were female.

Conventional plain radiographs relevant to mandibular fractures were obtained to confirm the presence of fractures. Pre- and posttrauma photographs and study models were used when necessary to aid treatment planning and assess the outcome of treatment. The degree of preoperative facial pain and trismus was measured on the 3rd postinjury day in all the patients. The subjects were evaluated preoperatively for trismus and pain in a blinded manner by a single examiner (Michael Ubong Obaji). Using a calibrated caliper, trismus was evaluated in millimeters by measuring the distance between the incisal edges of the upper and lower central incisors at the maximum mouth opening. The measurement of pain intensity was made according to a 10-point visual analogue scale, with the patients indicating their pain intensity within a range from no pain (0) to severe/unbearable pain (10). The patients' oral hygiene status was also assessed and graded using a gross plaque scoring method $(+=$ good, $++=$ fair, $+++=$ poor).

The subjects were treated under the same surgical protocol. Active treatments of the mandibular fractures were done by manual reduction and fixation under general anesthesia on the 3rd posttrauma day. Fixation was by maxilla-mandibular fixation using mandibular and maxillary arch bars with $0.5-\mathrm{mm}$ stainless steel tie wires, and the period of immobilization lasted for 6 weeks in each case. Following surgery, the patients were placed on i.v. Ampiclox, $500 \mathrm{mg}$ every $6 \mathrm{~h}$, i.v. metronidazole, $500 \mathrm{mg}$ every $8 \mathrm{~h}$, and i.m. pentazocine, $30 \mathrm{mg}$ every $6 \mathrm{~h}$ for $24 \mathrm{~h}$. From the $2 \mathrm{nd}$ postoperative day, the patients commenced oral clindamycin, $150 \mathrm{mg}$ every $12 \mathrm{~h}$ for 10 days, and oral naproxen sodium, $550 \mathrm{mg}$ every $12 \mathrm{~h}$ for 5 days. In the event of discomfort due to pain, the patients were advised to use paracetamol, 1,000 mg 6 hourly, pro re nata from the 7 th postoperative day. The surgical procedures and postoperative reviews were carried out by the same surgeon.

A minimum of eight visits was scheduled for each patient with an average interval of 1 week in the first 3 weeks, and fortnightly appointments in the subsequent 10 weeks, and thereafter 1-, 3- and 6 -monthly appointments in the follow-up period. The outcome of treatment was assessed from postoperative complaints, and clinical and radiological examination (where necessary) of patients as they presented during follow-up. Two weeks of domestic jaw exercise were recommended for all patients after the release of the maxilla-mandibular fixation. Those whose functional problems persisted after 8 weeks were referred to a physiotherapist.

Successful treatment was regarded as stable bone, a return to pretrauma esthetics, good mouth opening and occlusion, including the absence of clinical infection and pain at the fracture site during function. Complications were defined in this study as conditions that developed during and after treatment and persisted beyond 10 weeks from the commencement of treatment.

The data obtained were documented in a pro forma questionnaire including patient age, gender, oral hygiene status, degree of pain and trismus before treatment, follow-up findings and their management. The classification of signs and symptoms that developed in subjects during postoperative reviews was based on the World Health Organization criteria of 2005 [12]. These conditions were diagnosed in the same histopathological laboratory of this tertiary institution by the same pathologist (Martin Anazodo Nnoli). The data were analyzed with EPI Info 2008 software (CDC, 
Table 1. Age and gender distribution of subjects

\begin{tabular}{lcll}
\hline Age, years & Male, n (\%) & Female, n (\%) & Total, n (\%) \\
\hline $11-20$ & $11(13.3)$ & $3(3.6)$ & $14(16.9)$ \\
$21-30$ & $22(26.5)$ & $4(4.8)$ & $26(31.3)$ \\
$31-40$ & $16(19.3)$ & $3(3.6)$ & $19(22.9)$ \\
$41-50$ & $10(12.0)$ & $2(2.5)$ & $12(14.5)$ \\
$51-60$ & $4(4.8)$ & $3(3.6)$ & $7(8.4)$ \\
$61-70$ & $3(3.6)$ & $1(1.2)$ & $4(4.8)$ \\
$71-80$ & $0(0)$ & $1(1.2)$ & $1(1.2)$ \\
\hline Total & $66(79.5)$ & $17(20.5)$ & $83(100.0)$
\end{tabular}

Age: $\chi^{2}=162.821$, d.f. $=7, p=0.02$; gender: $\chi^{2}=162.821$, d.f. $=$ $7, \mathrm{p}=0.01$.

Table 2. Distribution of complications relative to the intensity of preoperative facial pain

\begin{tabular}{llll}
\hline Pain intensity & $\begin{array}{l}\text { Complications, } \\
\mathrm{n}(\%)\end{array}$ & $\begin{array}{l}\text { No complication, } \\
\mathrm{n}(\%)\end{array}$ & $\begin{array}{l}\text { Total, } \\
\mathrm{n}(\%)\end{array}$ \\
\hline $0-2.5$ & $0(0)$ & $31(37.4)$ & $31(37.4)$ \\
$2.6-5.0$ & $3(3.6)$ & $26(31.3)$ & $29(34.9)$ \\
$5.1-7.5$ & $2(2.4)$ & $11(13.3)$ & $13(15.7)$ \\
$7.6-10.0$ & $3(3.6)$ & $7(8.4)$ & $10(12.0)$ \\
\hline Total & $8(9.6)$ & $75(90.4)$ & $83(100.0)$ \\
\hline
\end{tabular}

$\chi^{2}=109.26$, d.f. $=9, \mathrm{p}=0.04$

Atlanta, Ga., USA). For analysis, simple frequency charts, descriptive statistics and tests of significance were used. Statistical significance was considered with $\mathrm{p}$ values $<0.05$. The statistical test of the study was powered at 0.75 .

\section{Results}

Of the 83 treated patients, 13 developed complications. The mean age of the patients was $36.7 \pm 11.3$ years. The overall male-to-female ratio was $5: 1$, which predominated in all the age categories except in the 7 th decade of life (table 1). The age $(\mathrm{p}=0.02)$ and gender $(\mathrm{p}=0.01)$ distribution of the subjects were statistically significant. The fractures were most common between 21 and 40 years of age $(n=45,54.2 \%)$. All the patients had sustained fractures in road traffic accidents, and these were located both on the right $(\mathrm{n}=45,54.2 \%)$ and left $(\mathrm{n}=38,45.8 \%)$ sides of the mandible. The fractures were favorable and ame-
Table 3. Distribution of complications relative to the preoperative limitation of mouth opening (trismus)

\begin{tabular}{llll}
\hline $\begin{array}{l}\text { Mouth opening, } \\
\mathrm{mm}\end{array}$ & $\begin{array}{l}\text { Complications, } \\
\mathrm{n}(\%)\end{array}$ & $\begin{array}{l}\text { No complication, } \\
\mathrm{n}(\%)\end{array}$ & $\begin{array}{l}\text { Total, } \\
\mathrm{n}(\%)\end{array}$ \\
\hline$<5$ & $5(6.0)$ & $25(30.1)$ & $30(36.1)$ \\
$6-10$ & $3(3.6)$ & $16(19.3)$ & $19(22.9)$ \\
$11-15$ & $2(2.4)$ & $19(22.9)$ & $21(25.3)$ \\
$16-20$ & $0(0)$ & $10(12.1)$ & $10(12.1)$ \\
$20-25$ & $0(0)$ & $3(3.6)$ & $3(3.6)$ \\
\hline Total & $10(12.0)$ & $73(88.0)$ & $83(100.0)$ \\
\hline \multicolumn{2}{c}{$\chi^{2}=109.26$, d.f. $=9, \mathrm{p}=0.03}$. \\
\hline
\end{tabular}

Table 4. Distribution of complications after treatment

\begin{tabular}{lc}
\hline Complication & $\mathrm{n}(\%)$ \\
\hline Impaired mastication & $10(24.4)$ \\
Facial asymmetry & $7(17.1)$ \\
Numbness of lower lip & $6(14.6)$ \\
Impaired mouth opening $(<35 \mathrm{~mm})$ & $5(12.2)$ \\
Occlusal derangement & $4(9.8)$ \\
Malunion & $3(7.3)$ \\
Nonunion & $3(7.3)$ \\
Reparative CGCG & $2(4.9)$ \\
Fibrous dysplasia & $1(2.4)$ \\
\hline Total & $41(100.0)$ \\
\hline
\end{tabular}

nable to reduction and immobilization by the closed reduction technique.

The oral hygiene status of the subjects was graded as fair and good. The number of patients decreased with increasing intensity of preoperative facial pain (table 2). However, the higher the intensity of facial pain, the more the complications that followed, and this was statistically significant $(\mathrm{p}=0.04)$. The distribution of complications relative to the preoperative limitations of mouth opening (trismus) is shown in table 3. The number of patients decreased with increasing interincisal distance. Conversely, the number of complications increased with decreasing interincisal distance, and this was statistically significant $(\mathrm{p}=0.03)$. The distribution of complications following treatment is provided in table 4 , which shows that impaired mastication and facial asymmetry were the most common $(\mathrm{n}=17,41.5 \%)$. There were the 3 nonunion cases, which eventually led to the development of central giant cell granuloma (CGCG) and fibrous dysplasia in the 
Table 5. Treatment of complications

\begin{tabular}{lc}
\hline Treatment & $\mathrm{n}(\%)$ \\
\hline Physiotherapy & $10(20.8)$ \\
Counseling & $10(20.8)$ \\
Occlusal grinding & $6(12.5)$ \\
Intermaxillary fixation & $6(12.5)$ \\
Partial denture prosthesis & $6(12.5)$ \\
Nonsteroidal anti-inflammatory drugs & $5(10.4)$ \\
Refracture & $2(4.2)$ \\
Enucleation and curettage & $2(4.2)$ \\
Paring down of bone & $1(2.1)$ \\
\hline Total & $48(100.0)$ \\
\hline
\end{tabular}

affected patients. Two of these CGCG cases occurred in an 18-year-old male while the other was in a 76-year-old female, and the lesions occurred 26 and 37 months after the fractures were sustained, respectively. Fibrous dysplasia manifested in a 20 -year-old female 21 months after the fracture. The various treatments of complications are shown in table 5 , with physiotherapy $(\mathrm{n}=10,20.8 \%)$ being the most common form. Two of the malunion cases were treated by refracture and maxilla-mandibular fixation, while the third was corrected by occlusal grinding. The 3 nonunion cases were initially treated by debridement and intermaxillary fixation, and the maxilla-mandibular fixation was left in situ for a period of 8 weeks. The CGCG and fibrous dysplasia were later treated by enucleation and curettage, and paring down of dysplastic bone, respectively.

The mean follow-up for the 83 patients was $43.4 \pm 6.8$ months (range 36-56). All complications were successfully treated during the follow-up period.

\section{Discussion}

This study showed that the higher the intensity of preoperative facial pain and the lower the interincisal distance on the 3rd posttrauma day (when the unilateral mandibular body fracture was treated by maxilla-mandibular fixation), the more the complications were significant. These variables were the direct and immediate consequence of the inflammatory response associated with the traumatic injuries that led to the fractures $[3,4]$. Webb et al. [6] observed that complication rates were lower when repair of mandibular fractures was delayed beyond $72 \mathrm{~h}$, and suggested that a delay in treatment was

Inflammatory Morbidity and Mandibular Body Fractures more cost-effective than early (immediate) treatment. Conversely, Biller et al. [1] reported that complications increased with treatment delay. The present study differed from these previous reports $[1,6]$ as substance abuse was cited in both as a risk factor in the development of complications, and the method of treatment was by rigid internal fixation, while the role of posttraumatic pain and trismus were not assessed. However, Hermund et al. [5] and Hurrell and Batstone [13] reviewed the literature and stated that with the current research evidence based on treatment outcome a definitive conclusion cannot be drawn on the optimal timing of the treatment of mandibular and other facial fractures.

As a result of the face not being protected, the impact of road traffic accidents in the orofacial region cannot be overemphasized as it always leaves tissue injury characterized by hyperemia, vasodilatation and increased capillary permeability with fluid accumulation in the interstitial space followed by granulocyte and monocyte migration, which results from the increased osmotic pressure within the capillaries $[14,15]$. These events, which are more intense within the first 3 days following injury, lead to pain and facial edema that clinically manifest with varying degrees of limitation of mouth opening (trismus), swelling and reduced masticatory capability [16]. Edema is the expression of exudates or transudation, and posttraumatically both events occur together. The severity of the edema, pain and trismus will depend on the severity of the impacting force and the host response to such an external stimulus $[14,15]$. This explains the variability in the degree of response to pain and trismus among the patients documented in the present study. However, the orofacial morbidities resulting from the edema, such as pain, trismus and swelling, are serious issues as they affect the ability of the patients to interact with others and return to their routine social and working life $[5,6]$. Also, fractures of the mandible can be complex, challenging and sometimes may have a significant impact on a patient's quality of life [1-4]. Previous studies [2-4] have shown that complications arising from mandibular fracture repair are multifactorial and that some of these factors have a significant impact on treatment outcome.

The present study showed that the more severe the limitations of mouth opening and facial pain, the greater the complications, and this significantly affected treatment outcome. This may be because the factors influencing the outcome of treatment of mandibular fractures are multifactorial and complex. This finding is similar to previous observations [3-5] but contrary to those of Biller et al. [1] and Furr et al. [2], although, unlike the present 
study, their studies were all retrospective, treatments were done by open reduction and mini-plate osteosynthesis, and the type of fracture was not restricted to isolated unilateral compound mandibular body fractures. Biller et al. [1] showed that repair of mandibular fractures after 3 days of injury led to increased complications, such as weakness of the marginal mandibular nerve, malocclusion, exposed hardware and persistent pain, while those treated earlier did not show a greater incidence of complications. The outcome of treatment in the present study could have been influenced by other factors, such as the genetic disposition of the patients, age and type of fracture, method of treatment, factors related to the surgeon, and patient compliance to postoperative instructions, among others. The oral hygiene status of the patients, which were graded as fair and good, could not have contributed to the development of complications as no case of infection was recorded. This absence of infection might also have been due to the fact that there was no intraoral wound communication and the resultant therapeutic effects of the use of antibiotics. However, Worsaae and Thorn [17] reported that the emergence of complications following treatment of mandibular fractures may also be due to the inability of patients to overcome the different neuromuscular and functional problems associated with the repositioning of the fractured segments.

The common age of occurrence of mandibular fractures and gender disposition in the present study is similar to those of previous studies $[7,18]$. The complication rate of $15.7 \%$ is within the $5.0-46.0 \%$ range in an earlier report [18]. The findings also confirmed the assertion that complications of mandibular fractures can occur at any age and affect both genders $[1,2,19]$.

The complications and their treatments recorded in the present study have been documented by earlier researchers [20-22]. The outcome of this study also suggests that trauma has a role in the etiology of CGCG and fibrous dysplasia as these conditions were seen in $2(4.9 \%)$ and $1(2.4 \%)$ of the subjects, respectively, an observation which has also previously been documented [23, 24]. It has been stated that levels of the transcription factor c-Fos are raised in fibrous dysplasia, leading to jaw overexpression and a resultant dysplastic change in bone. Although the pathogenesis of this is poorly understood [25], genetics, trauma, endocrine disturbances and a molecular basis have been mentioned as being involved [23]. Some researchers believe that it is caused by mutation in the GNAS (guanine nucleotide-binding protein/a-subunit) gene on chromosome 20 , which occurs postzygotically $[26,27]$.
The etiology of CGCG is still not fully understood, but is thought to be a reactive process to some unknown stimuli. It has been hypothesized that it is the mononuclear spindle-shaped cell (fibroblast or fibroblast-like) that controls the proliferative activity of this lesion, as opposed to the more frequently seen giant cell [28]. This is indicated by the expression of the cell cycle protein Ki-67 in CGCG [29, 30].

The limitations of this study include the inability to determine the pretrauma facial size, facial swelling, and the unavailability and unaffordability of mini-plates at our institution; hence rigid internal fixation was not used in the treatment of mandibular body fractures or of malunion and nonunion complications. Furthermore, the follow-up of patients in our location is poor.

\section{Conclusion}

This study has shown that posttrauma pain and trismus due to unilateral mandibular body fractures are associated with the development of complications. Because early reduction with rigid fixation for compound fractures was not possible, a modified approach was used, and this could be useful specifically in centers that are less well equipped and where access to rigid fixation is limited. In such centers, patients with a great deal of swelling and edema should have their treatment delayed beyond 3 days to allow a reduction of inflammatory morbidities. An adequately powered prospective study treating patients at 5 or 7 days is required to make the case for later intervention.

\section{Acknowledgement}

The authors are grateful to the dental surgeon and nurses at the Department of Dental Surgery, University of Calabar Teaching Hospital, Nigeria, who assisted with the management of the patients.

\section{Disclosure Statement}

The authors declare that they have no conflicts of interest. 


\section{References}

$>1$ Biller JA, Pletcher SD, Goldberg AN, et al: Complications and the time to repair mandible fractures. Laryngoscope 2005;115:769772.

-2 Furr AM, Schweinfurth JM, May WL: Factors associated with long-term complications after repair of mandibular fractures. Laryngoscope 2006;116:427-430.

3 Maloney PL, Lincoln RE, Coyne CP: A protocol for the management of compound mandibular fractures based on the time from injury to treatment. J Oral Maxillofac Surg 2001; 59:879-884.

4 Stone IE, Dodson TB, Bays RA: Risk factors for infection following operative treatment of mandibular fractures: a multivariate analysis. Plast Reconstr Surg 1993;91:64-68.

$\checkmark 5$ Hermund NU, Hillerup S, Kofod T, et al: Effect of early or delayed treatment upon healing of mandibular fractures: a systematic literature review. Dent Traumatol 2008;24:2226.

6 Webb LS, Makhijani S, Khanna M, et al: A comparison of outcomes between immediate and delayed repair of mandibular fractures. Can J Plast Surg 2009; 17:124-126.

$>7$ Anyanechi CE, Chukwuneke FN, Saheeb BDO: Mandibular fracture and complications associated with different treatment methods: review of literature. Ebonyi Med J 2010;9:2-7.

8 Anyanechi CE, Bassey GO: Non-union of mandibular fractures in Calabar, south-south Nigeria: a ten year review. Int J Trop Surg 2009;3:131-137.

$>9$ Anyanechi CE, Chukwuneke FN: Prognosis of teeth in the line of mandibular fracture: 5 -year clinical and radiological follow-up. Niger J Med 2013;22:61-63.
10 Li Z, Zhang W, Li ZB, et al: Abnormal union of mandibular fractures: a review of 84 cases. J Oral Maxillofac Surg 2006;64:1225-1231.

11 Mathog RH, Toma V, Clayman L, et al: Nonunion of the mandible: an analysis of contributing factors. J Oral Maxillofac Surg 2000;58: 746-752.

12 Barnes L, Everson JW, Reichart P, et al (eds): Pathology \& Genetics: Head and Neck Tumours. Lyon, IARC Press, 2005, pp 284-327.

13 Hurrell MJ, Batstone MD: The effect of treatment timing on the management of facial fractures: a systematic review. Int J Oral Maxillofac Surg 2014;43:944-950.

14 Berne RM, Levy MN, Koeppen BM, et al: Physiology, ed 5. New York, Elsevier, 2004.

15 Hupp JR: Wound repair; in Peterson LJ, Ellis E, Hupp JR, Tucker MR (eds): Contemporary Oral and Maxillofacial Surgery, ed 3. St Louis, Mosby, 1998, pp 58-60.

16 Barker DA, Oo KK, Alak A, et al: Timing for repair of mandible fractures. Laryngoscope 2011;121:1160-1163.

17 Worsaae N, Thorn JJ: Surgical versus nonsurgical treatment of unilateral dislocated low subcondylar fractures: a clinical study of 52 cases. J Oral Maxillofac Surg 1994;52:353360.

18 Rowe NL, Williams J: Maxillofacial Injuries, ed 2. Edinburgh, Churchill Livingstone, 1994, pp 825-864.

19 Dahstrom L, Kahnberg K, Lindahl L: 15 year's follow-up on condylar fractures. Int J Oral Maxillofac Surg 1989;18:18-23.

20 Haug RH, Assael LA: Outcomes of open versus closed treatment of mandibular subcondylar fractures. J Oral Maxillofac Surg 2001; 59:320-323.
21 Hyde N, Manisali M, Aghabeigi B: The role of open reduction and internal fixation in unilateral fractures of the mandibular condyle: a prospective study. Br J Oral Maxillofac Surg 2002;40:19-22.

22 Luz JGC, Moraes RB, D’Avilla RP, et al: Factors contributing to the surgical retreatment of mandibular fractures. Braz Oral Res 2013; 27:258-265.

23 Malik NA: Textbook of Oral and Maxillofacial Surgery, ed 2, New Delhi, Jaypee, 2008, pp 439-512.

24 Sato M, Tanaka N, Sato T: Oral and maxillofacial tumours in children: a review. Br J Oral Maxillofac Surg 1997;35:92-95.

25 Kashima TG, Nishiyama T, Shimazu K, et al: Periostin, a novel marker of intra-membranous ossification, is expressed in fibrous dysplasia and in c-Fos overexpresssing bone lesions. Hum Pathol 2009;40:226-237.

26 Lustig LR, Holliday MJ, McCarthy EF, et al: Fibrous dysplasia involving the skull base and temporal bone. Arch Otolaryngol Head Neck Surg 2001;127:1239-1247.

27 Kuznetsov SA, Cherman N, Riminucci M, et al: Age-dependent demise of GNAS-mutated skeletal stem cells and mormalization of fibrous dysplasia of bone. J Bone Miner Res 2008;23:1731-1740.

28 Chattaha MR, Ali K, Aslam A, et al: Current concepts in central giant cell granuloma. Pakistan Oral Dent J 2006;26:71-78.

29 O’Malley M, Pogrel MA, Stewart JC, et al: Central giant cell granulomas of the jaws: phenotype and proliferation-associated markers. J Oral Pathol Med 1997;26:159-164.

30 Tiffee JC, Aufdemorte TB: Markers for macrophage and osteoclasts lineages in giant cell lesions of the oral cavity. J Oral Maxillofac Surg 1997;55:1108-1112. 